\title{
The effect of sweet potato powder on the physical, chemical and organoleptic indicators of bread quality
}

\author{
G.G Yusupova ${ }^{1}$, and R.Kh Yusupov ${ }^{2}$ \\ ${ }^{1}$ PhD Sciences, Russian State Agricultural University-Moscow Agricultural Academy named after K.A. Timiryazev, 127550, Moscow, \\ Street. Timiryazevskaya, 49, Russia \\ ${ }^{2} \mathrm{PhD}$ Sciences, Russian State Agricultural University-Moscow Agricultural Academy named after K.A. Timiryazev, 127550, Moscow, \\ Street. Timiryazevskaya, 49, Russia
}

\begin{abstract}
In the diet of the population of West African countries, there is a shortage of macro- and micronutrients, which negatively affects people's health. Bakery products traditionally occupy a significant part in the diet. Sweet potato is a promising ingredient in the enrichment of bakery products. Sweet potato ranks seventh among crops in terms of prevalence and use in nutrition, because It is an unpretentious plant, resistant to drought, pests, diseases and can grow in flooded soils. An analysis of the data of finished products obtained by adding sweet potato powder obtained by infrared drying sweet potato powder into the dough in the amount of $5 \%$ and $10 \%$ by weight of flour showed that the shape stability of the samples increased by $4 \%$ and $2 \%$ compared to the control. When adding sweet potato powder in an amount of $10 \%$, the specific volume increased by $6 \%$, porosity - by $3 \%$, acidity - by $25-37 \%$ compared with the control. When making juice from sweet potato in an amount of 50-70\%, the specific volume of products increased by $9-21 \%$ compared with the control sample. The largest specific volume was possessed by products with the addition of sweet potato juice in an amount of $70 \%$ instead of the mass of water according to the product recipe. The acidity of bread increased by $6 \%$ in samples with the introduction of juice for 50 and $60 \%$, and by $12 \%$ in the bread sample with the introduction of juice for $70 \%$. The porosity of the crumb of bread increased slightly. A technique is proposed for determining the rational dose of adding powder and sweet potato juice to bread.
\end{abstract}




\section{Introduction}

In the diet of the population of West Africa, in particular Benin, there is a shortage of macro and micronutrients, which negatively affects people's health. Bakery products traditionally occupy a significant part of the diet, so the enrichment of their composition with biologically active substances will solve the problem of deficiency of macro- and micronutrients. A promising ingredient in the enrichment of bakery products is yam.

Wheat, as a crop, is not grown on the territory of West Africa due to adverse climatic conditions. Wheat flour, which is the main ingredient in the preparation of bakery products, is imported from other countries; therefore, the introduction of sweet potato products into the composition of bakery products will not only increase the nutritional value of products, but also reduce the cost of production.

Sweet potato ranks seventh among crops in terms of prevalence and use in nutrition, because It is an unpretentious plant, resistant to drought, pests, diseases and can grow in flooded soils. The sweet pulp contains dietary fiber (up to $49.7 \%$ ) such as pectin (39.5\%), cellulose, hemicellulose, lignin, which have functional properties. In addition, sweet potato contains a high content of biologically active substances: flavonoids, phenolic compounds, carotenoids, which are antioxidants. For example, orange sweet potato varieties contain from 14 to $128.5 \mathrm{mg} / \mathrm{g}$ carotenoids per dry matter. Powders have the convenience of entering into the recipe, the high safety of macro- and micronutrients; occupy a smaller volume, optimizing logistics and storage. In addition, the use of freshly squeezed juice instead of part of the water during kneading, allows you to enrich products with macro- and micronutrients, improve taste, aroma and appearance.

Research on the development of technology for bakery products using sweet potato has not been conducted enough, therefore, the development of technology for bakery products using sweet potato, which replenish the missing biologically valuable components of the human body, is an urgent task aimed at improving the health and quality of life of the people of West Africa. Therefore, any efforts aimed at the effective use of wheat flour; replacing part of wheat flour with readily available flour from raw materials most common in African countries in bakery is a way out of this situation.

In order to achieve the specified requirements, various raw materials, traditional for African countries, are used in bakery. In connection with the above, relevant is:
1. Expanding the range of bakery products in Africa through the use of powders of products of processing of local plant materials, for example, sweet potato, when baking bread.

2. Improving the efficiency and rational use of wheat flour, replacing part of it with powders from available local starch-containing plant materials.

3. Improving the quality of bread through the use of additives from vegetable powders.

4. Stimulating the improvement of the efficiency of cultivation of sweet potato (by expanding the assortment and increasing the volume of cultivation of crops) while reducing the cost of production in the drying process.

\section{Research methodology and results}

At the FGANI Research Institute of the Bakery Industry, studies were carried out on the effect of sweet potato powder on the physicochemical parameters of bread from the composition of premium and sweet wheat flour. Bakery products were prepared from a mixture of wheat and sweet potato flour.

An analysis of the data of finished products obtained by adding sweet potato powder obtained by infrared drying into the dough in the amount of $5 \%$ and $10 \%$ by weight of flour showed that the shape stability of the samples increased by $4 \%$ and $2 \%$ compared with the control. It was found that when sweet potato powder was added in an amount of up to $10 \%$, the specific volume increased by $6 \%$, porosity - by $3 \%$, acidity - by $25-37 \%$ compared with the control. The increase in specific volume and porosity is probably due to the accumulation of a greater amount of carbon dioxide during fermentation due to the significant content of substances that stimulate the vital activity of microorganisms (sugars, mineral salts, vitamins, amino acids) in the sweet potato powder.

(Below, we denote the name of sweet potato powder obtained by the technology based on the use of infrared drying with the abbreviation PPIF1).

The introduction of sweet potato powder more than $10 \%$ by weight of flour reduced the specific volume of bread. A large volume of bread is a commercial advantage. A decrease in the volume of bread when introducing PBIF1 is an undesirable economic quality for bakers, since consumers are often attracted to bakery products with a large weight and volumetric yield. An analysis of studies of the physicochemical parameters of bread confirmed that the most effective dose of PBIF1 from the flour weight is $5 \ldots 10 \%$. 

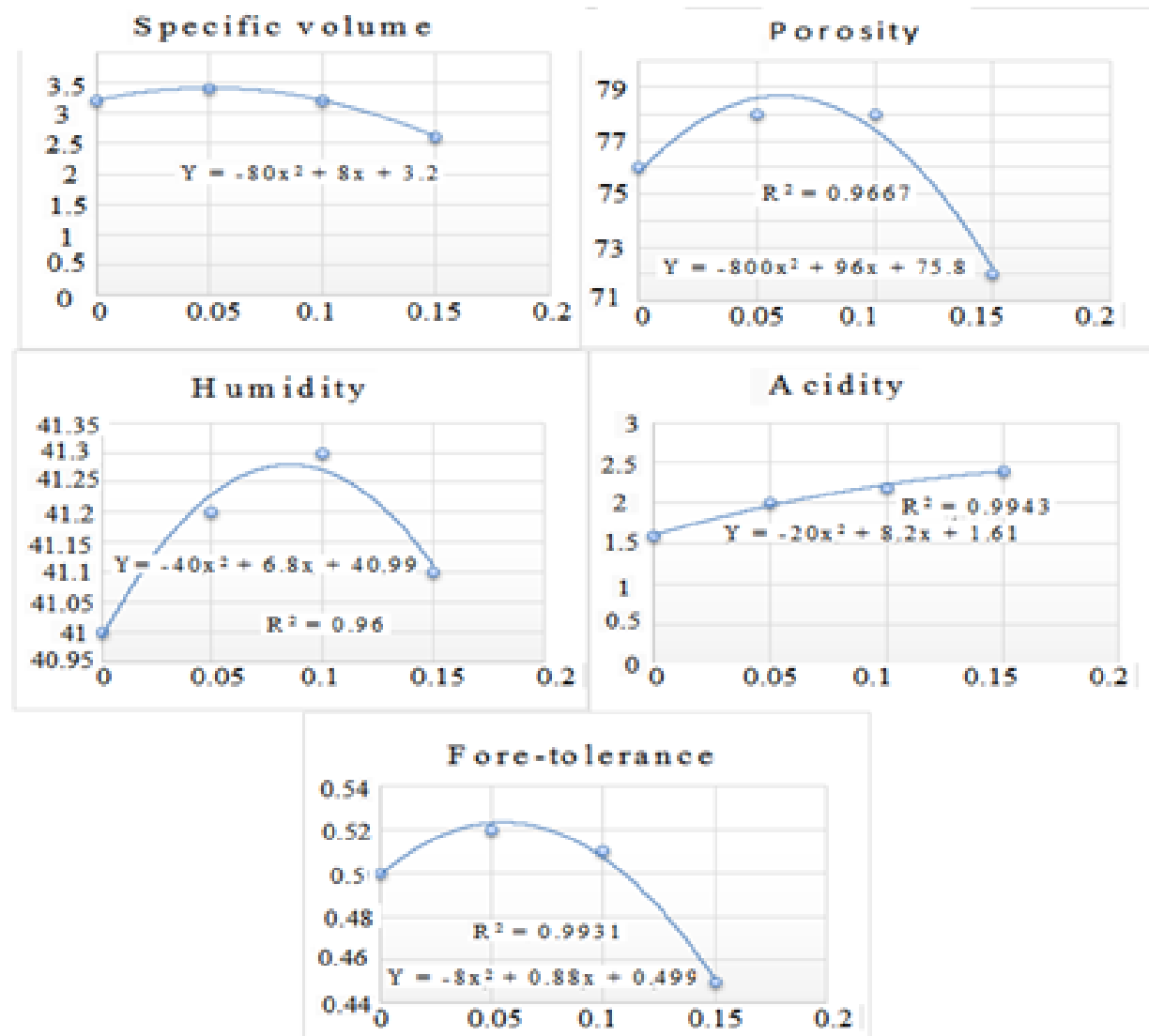

Fig. 1. Approximation of experimental data and the regression equation for the physical and chemical parameters of bread when addingPPIF1 in the amount of $0 ; 5 ; 10 ; 15 \%$.

According to the data presented in Figure 1, a certain increase in the moisture of the bread crumb should be noted, which can be explained by the water-holding properties of sweet potato powder, the ability to form viscous gels that retain water. There is a tendency to increase the specific volume of bread. This is explained by the fact that when the powder from sweet potato is added to the dough, fermentation processes are intensified due to the vitamins and minerals contained in the powder, which are additional nutrition for yeast on the one hand, and on the other, the redox effect of amino acids contained in the sweet potato powder has a positive effect on ripening dough.

The addition of sweet potato powder not only contributes to the rapid maturation of the dough, but also improves the quality of the finished product. The acidity of the crumb of bread with continued fermentation of the powder from sweet potato gradually increased.
Moreover, the maximum value was obtained after 150 min of the fermentation process. The results are shown in Figure 1 and in table 1.

Table 1. Physical and -chemical characteristics of bread with the introduction of PPIF1 content.

\begin{tabular}{|c|c|c|c|c|c|}
\hline \multirow{2}{*}{$\begin{array}{l}\text { Sampl } \\
\text { e with } \\
\text { sweet } \\
\text { potato } \\
\text { powde } \\
\text { r, \% }\end{array}$} & \multicolumn{5}{|c|}{ The name of indicators } \\
\hline & $\begin{array}{c}\text { Specif } \\
\text { ic } \\
\text { volum } \\
\text { e, } \\
\mathrm{Cm3} / \\
\text { g }\end{array}$ & $\begin{array}{c}\text { Porosity, } \\
\%\end{array}$ & $\begin{array}{c}\text { Humidi } \\
\text { ty of } \\
\text { bread, } \\
\%\end{array}$ & $\begin{array}{c}\text { Acidi } \\
\text { ty of } \\
\text { bread } \\
, \\
\text { degre } \\
\text { e }\end{array}$ & $\begin{array}{c}\text { Form } \\
\text { stabilit } \\
\text { y, H / } \\
\text { D }\end{array}$ \\
\hline 0 & 3.2 & 76.0 & 41.0 & 1.6 & 0.5 \\
\hline 5 & 3.4 & 78.0 & 41.2 & 2.0 & 0.52 \\
\hline 10 & 3.2 & 78.0 & 41.3 & 2.2 & 0.51 \\
\hline 15 & 2.6 & 72.0 & 41.1 & 2.4 & 0.45 \\
\hline $\mathrm{H}_{\mathrm{cp} 0.05}$ & 0.2 & 1.9 & 1.0 & 0.2 & 0.05 \\
\hline
\end{tabular}


Table 3. Effect of a dose of sweet potato juice on the physical and chemical quality indicators of premium wheat bread.

\begin{tabular}{|c|c|c|c|c|c|}
\hline $\begin{array}{c}\text { Sample with } \\
\text { sweet potato } \\
\text { powder \% }\end{array}$ & $\begin{array}{c}\text { Specific volume, } \\
\mathbf{C m 3} / \mathbf{g}\end{array}$ & Porosity,\% & $\begin{array}{c}\text { Humidity of bread, } \\
\mathbf{\%}\end{array}$ & $\begin{array}{c}\text { Acidity of bread, } \\
\text { degree }\end{array}$ & $\begin{array}{c}\text { Form stability, H / } \\
\text { D }\end{array}$ \\
\hline Control & 3.2 & 76.0 & 41.0 & 1.6 & 0.50 \\
\hline 50 & 3.5 & 77.0 & 38.8 & 1.7 & 0.52 \\
\hline 60 & 3.6 & 77.0 & 38.8 & 1.7 & 0.53 \\
\hline 70 & 3.9 & 77.0 & 37.1 & 1.8 & 0.55 \\
\hline $\mathrm{H}_{\text {нср } 0.05}$ & 0.2 & 1.0 & 1.0 & 0.1 & 0.05 \\
\hline
\end{tabular}

In the process of fermentation and subsequent baking, the fats of the powder are split from sweet potato, which leads to the appearance of free fatty acids, which increase acidity. At the same time, organic acids accumulate as by-products in the test. And since the fermentation time in this embodiment was longer, the content of the above acids was greater. The introduction of this powder increases the acidity of the dough, helps to improve the taste and aroma of the products. Nitrogen, mineral and other nutrients of sweet potato not only contribute to the intensification of the rate of development of yeast. After 45 minutes, one can observe an improvement in the physicochemical properties of the test as compared with the control (60 min fermentation).

This is due to the use of sweet potato powder in the process of making bread, which reduced the fermentation time of the dough and improved its quality indicators. Analyzing the organoleptic characteristics of bread (Figure 2), table 2, we can notice the positive effect of PBIF1 on all indicators. The bread samples had a convex, light yellow crust, elastic, yellow crumb with an orange tint and a peculiar sweet potato flavor. Based on our studies, we have shown the possibility of using a mixture of PBIF1 with premium wheat flour in the recipe, and their dosage has been established to improve the consumer properties of bread.

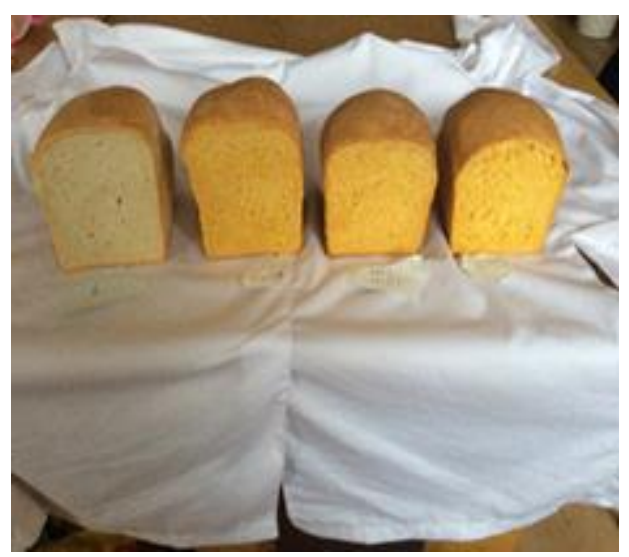

Fig. 2. Samples of bread with the Introduction of PBIF1 from left to right, in quantity $0 ; 5 ; 10$ and $15 \%$ by section.

\section{The effect of sweet potato juice on the physical, chemical and organoleptic indicators of bread quality}

We studied the effect of sweet potato juice on the organoleptic and physicochemical parameters of wheat

Table 2. Effect of sweet potato powder on organoleptic indicators of bread quality.

\begin{tabular}{|c|c|c|c|c|}
\hline \multirow{3}{*}{ The name of indicators } & \multicolumn{4}{|c|}{ Bread quality indicators } \\
\hline & \multirow[t]{2}{*}{ The control } & \multicolumn{3}{|c|}{ with sweet potato powder, $\%$ by weight of flour } \\
\hline & & 5 & 10 & 15 \\
\hline Form & \multicolumn{4}{|c|}{ Corresponds to bread form, without lateral outflows } \\
\hline The surface & \multicolumn{4}{|c|}{ Is smooth, smooth, without cracks and blasts } \\
\hline Peel color & Brown & \multicolumn{3}{|l|}{ Light Yellow } \\
\hline Peel form & Convex & Convex & Convex & Convex \\
\hline Condition of crumb & \multicolumn{4}{|l|}{ Elastic, elastic crumb } \\
\hline Crumbs color & $\begin{array}{l}\text { White with a yellowish } \\
\text { tint }\end{array}$ & \multicolumn{3}{|c|}{ Yellow with a reddish tint } \\
\hline Porosity state & \multicolumn{2}{|l|}{ Thin-walled uniform } & Medium uniform & $\begin{array}{l}\text { Medium } \\
\text { uneven }\end{array}$ \\
\hline Taste & Intrinsic & $\begin{array}{l}\text { Intrinsic with a slight } \\
\text { aftertaste sweet potato }\end{array}$ & $\begin{array}{l}\text { Inherent with smack of } \\
\text { sweet potato }\end{array}$ & $\begin{array}{l}\text { Inherent with } \\
\text { smack of } \\
\text { sweet potato }\end{array}$ \\
\hline Odor & Intrinsic & $\begin{array}{l}\text { Intrinsic with a faint } \\
\text { aroma Sweet potato }\end{array}$ & $\begin{array}{l}\text { Inherent with the aroma } \\
\text { of sweet potato }\end{array}$ & $\begin{array}{l}\text { Inherent with } \\
\text { the aroma of } \\
\text { sweet potato }\end{array}$ \\
\hline
\end{tabular}


dough (Figure 3). The results of the study are presented in table 3. (Below, we denote the name of sweet potato juice obtained by the technology based on the use of spin cycle with the abbreviation JP).

It was found that the introduction of juice from sweet potato in an amount of $50-70 \%$, the specific volume of products increased by $9-21 \%$ compared with the control sample. The largest specific volume was possessed by products with the addition of sweet potato juice in an amount of $70 \%$ instead of the mass of water according to the product recipe. The acidity of bread increased by $6 \%$ in samples with the introduction of juice for 50 and $60 \%$, and by $12 \%$ in the bread sample with the introduction of juice for $70 \%$. The porosity of the crumb of bread increased slightly.

An analysis of the studies of the physicochemical parameters of bread with the addition of juice from sweet potato showed (table 4) that the products with the addition of $70 \%$ SB by weight had the best performance. Analyzing the organoleptic characteristics presented in Table 4, we can notice the positive effect of SB on all indicators: the bread had a convex, light yellow crust, elastic, saturated yellow crumb with a reddish tinge and characteristic of sweet potato flavor.

The data obtained indicate that the introduction (SB), leads to an improvement in organoleptic and physical and chemical indicators of product quality, the volume of products increases, the porosity increases. With an increase for juice introduced, the acidity of the products somewhat increases, but in general it remains at the level of acceptable standards.

\section{Establishing the relevance of quality indicators}

The degree of significance of indicators is estimated by the coefficient of weight. The interval of change of coefficients is set within the range of $0-1 ; 0-10 ; 0-100$. It is important that the sum of the weighting coefficients should be constant and be $1 ; 10 ; 100$.

There are various methods for determining weight.
The most commonly used expert method, in particular, ranking. According to the requirements and provisions established in the standards (GOST 15467-79), two groups of methods for determining weighting factors are used in assessing consumer properties and quality indicators of goods:

1) Analytical methods for determining weight (these methods include the method of regression dependencies, the method of equivalent relations)

2) Expert methods for determining weight (these methods of quality assessment include the method of preference (or evaluation), the ranking method, the pairwise comparison method, the method of sequential comparisons).

The ranking of selected indicators of the quality of bread was carried out with the involvement of expert evaluation. The ranking results are shown in tables 5 and 6.

Table 5. Determination of the coefficient of gravity (mi).

\begin{tabular}{|c|c|c|c|}
\hline Quality indicators & № & Rank & $\begin{array}{c}\text { Gravity } \\
\text { coefficient }\end{array}$ \\
\hline Humidity & 1 & 3.8 & 0.26 \\
\hline Acidity & 2 & 3.8 & 0.26 \\
\hline Porosity & 3 & 4.6 & 0.22 \\
\hline Specific volume & 4 & 4.8 & 0.21 \\
\hline Form stability & 5 & 4.2 & 0.24 \\
\hline
\end{tabular}

They formed the expert estimates after familiarization with the technical documentation, product characteristics, research data, and documentation and calculation materials. To confirm the correctness of the choice of quality indicators made, it is advisable to assess the degree of consistency of expert opinion: if the consistency is high, it is considered that the choice of indicators is successful. We assess the degree of consensus using the method of rank correlation using the coefficient of concordance $\mathrm{W}$.

The average value of the total ranks:

Table 4. Effect of the dose of sweet potato juice on organoleptic indicators of the quality of bread from wheat flour of the highest grade.

\begin{tabular}{|c|c|c|c|c|}
\hline \multirow{3}{*}{$\begin{array}{l}\text { The name of } \\
\text { indicators }\end{array}$} & \multicolumn{4}{|c|}{ Bread quality indicators } \\
\hline & \multirow[t]{2}{*}{ Control } & \multicolumn{3}{|c|}{ with sweet potato juice, $\%$ instead of the mass of water as calculated } \\
\hline & & 50 & 60 & 70 \\
\hline Form & \multicolumn{4}{|c|}{ Corresponds to bread form, without lateral outflows } \\
\hline The surface $b$ & \multicolumn{4}{|c|}{ Is smooth, smooth, without cracks and blasts } \\
\hline Peel color & Brown & \multicolumn{3}{|c|}{ Light Yellow } \\
\hline Peel form & \multicolumn{4}{|c|}{ Convex } \\
\hline $\begin{array}{l}\text { Condition of } \\
\text { crumb }\end{array}$ & \multicolumn{4}{|c|}{ Elastic, elastic crumb } \\
\hline Crumbs color & $\begin{array}{l}\text { White with a } \\
\text { yellowish tint }\end{array}$ & \multicolumn{3}{|c|}{ Saturated yellow with a reddish tint } \\
\hline Porosity state & \multicolumn{4}{|c|}{ Thin-walled, uniform } \\
\hline Taste & Intrinsic & $\begin{array}{l}\text { Peculiar with a taste } \\
\text { of sweet potato }\end{array}$ & $\begin{array}{l}\text { Peculiar with a taste } \\
\text { of sweet potato }\end{array}$ & $\begin{array}{l}\text { Peculiar with a taste of } \\
\text { sweet potato }\end{array}$ \\
\hline Odor & Intrinsic & $\begin{array}{l}\text { Peculiar with sweet } \\
\text { potato flavor }\end{array}$ & $\begin{array}{l}\text { Peculiar with sweet } \\
\text { potato aroma }\end{array}$ & $\begin{array}{l}\text { Peculiar with sweet } \\
\text { potato aroma }\end{array}$ \\
\hline
\end{tabular}




$$
R_{i}=\frac{\sum_{1}^{n} R_{i}}{n}=21.2
$$

The deviations of the total ranks Ri from the average $\hat{R} i$ and the squares of these deviations are shown in table 6.

The sum of the squares of the deviations of the total ranks $\mathrm{R}_{-} \mathrm{i}$ from the average value $\hat{\mathrm{R}}_{-} \mathrm{i}$ :

$$
S=\sum_{1}^{n}\left(R_{i}-R_{i}\right)^{2}=21
$$

According to the Candela formula, we determine the concordance coefficient $\mathrm{W}$ :

$$
W=\frac{12 S}{m^{2}\left(n^{2}-n\right)}=0.5,
$$

m - Number of experts involved;

$\mathrm{n}$ - The number of quality indicators of bakery products

The obtained value of the concordance coefficient $\mathrm{W}$ $=0.5$ allows us to assume that the consistency of expert opinions is noticeable.

The next step is to determine the rational (weighted average) dose of the additive ßvvs calculated by the formula:

$$
\beta_{63 \mathrm{~B}}=\frac{\sum_{i=1}^{n} \beta_{i} m_{i}}{\sum_{i=1}^{n} m_{i}},
$$

Bi - is the dose of the additive corresponding to the maximum of the i-th quality indicator; determined by the graphs (Figures 1, 5) obtained by the regression equations.

$\mathrm{mi}$ - is the weighting coefficient.

$$
\begin{aligned}
& \beta_{\text {vavPPFI }}=[(7 \times 0.21)+(6 \times 0.22)+(8 \times 0.26)+ \\
& +(15 \times 0.26)+(5 \times 0.24)] / 1.19=9.77 / 1.19=8.2 \% \\
& \beta_{\text {vavPPFI }}=[(70 \times 0.21)+(60 \times 0.22)+(5 \times 0.26)+ \\
& +(70 \times 0.26)+(70 \times 0.24)] / 1.19=64.2 / 1.19=53.95 \%
\end{aligned}
$$

Using the graphs in figures 1, 3 we find the values of

\begin{tabular}{|c|c|c|c|c|c|}
\hline \multirow[b]{2}{*}{ Experts } & \multicolumn{5}{|c|}{ Quality indicators of wheat flour bread } \\
\hline & Humidity & Acidity & Porosity & $\begin{array}{l}\text { Specific } \\
\text { volume }\end{array}$ & $\begin{array}{c}\text { Form } \\
\text { stability }\end{array}$ \\
\hline 1 & 4 & 4 & 5 & 5 & 4 \\
\hline 2 & 4 & 4 & 4 & 5 & 4 \\
\hline 3 & 3 & 3 & 5 & 5 & 5 \\
\hline 4 & 4 & 4 & 5 & 4 & 4 \\
\hline 5 & 4 & 4 & 4 & 5 & 4 \\
\hline Average value & 3.8 & 3.8 & 4.6 & 4.8 & 4.2 \\
\hline Total rank & 19 & 19 & 23 & 24 & 21 \\
\hline \multicolumn{6}{|c|}{ The average value of the total rank $\hat{\mathrm{R}}_{\mathrm{i}}=21,2$} \\
\hline $\begin{array}{l}\text { Deviation squares } \\
\left(R_{i}-\hat{\mathrm{R}}_{i}\right)^{2}\end{array}$ & 4 & 4 & 4 & 9 & 0 \\
\hline
\end{tabular}
the quality indicators of bread for the weighted average values of additives PPIF, JP (table 9). As you can see, the indicators correspond to the normative values (table 8).

Some excess of porosity by $15 \%$ and shape stability by $15 \%$ is noted

Table 6. Ranking results. 
Table 8. The standard value of bakery quality indicators.

\begin{tabular}{|c|c|c|c|c|c|}
\hline Name bread sample & Moisture crumb, \% & $\begin{array}{c}\text { Acidity crumb, } \\
\text { degree }\end{array}$ & $\begin{array}{c}\text { Porosity } \\
\text { crumb, \%, }\end{array}$ & $\begin{array}{c}\text { Specific } \\
\text { volume, ml /g }\end{array}$ & $\begin{array}{c}\text { Form stability, } \\
\text { H/D }\end{array}$ \\
\hline $\begin{array}{c}\text { Wheat flour bread } \\
\text { top, grade }\end{array}$ & $39-46$ & $2-3.5$ & 68 & 3.5 & $0.44-0.45$ \\
\hline
\end{tabular}

Table 9. Values of quality indicators for bread products with rational (weighted average) doses of additives.

\begin{tabular}{|c|c|c|c|c|c|}
\hline \multirow{2}{*}{$\begin{array}{c}\text { Rational } \\
\text { (weighted } \\
\text { average) dose of } \\
\text { the additive } \\
\text { quality indicators }\end{array}$} & \multicolumn{5}{|c|}{ Показатели качества } \\
\hline & Humidity,\% & Acidity, degree & Porosity, \% & $\begin{array}{l}\text { Specific volume, } \\
\mathrm{cm}^{3} / \mathrm{g}\end{array}$ & $\begin{array}{c}\text { Form stability, } \\
\text { H/D }\end{array}$ \\
\hline \multicolumn{6}{|c|}{ Sweet Potato Bread } \\
\hline$\beta_{\mathrm{VZVPPFI}}=8.2 \%$ & 41.27 & 2.2 & 78.3 & 3.3 & 0.51 \\
\hline \multicolumn{6}{|c|}{ Хлеб с внесением сока батата } \\
\hline$\beta_{\mathrm{vzvJP}}=53.95 \%$ & 38.8 & 1.7 & 77 & 3.5 & 0.52 \\
\hline
\end{tabular}

\section{Conclusions}

As a result of the studies, the possibility of using a mixture of PBIF1 with premium wheat flour in the formulation was proved, and their rational dose of application was established, which ensures the improvement of consumer qualities of bread.

1. In the diet of the population of West African countries there is a shortage of macro- and micronutrients, which negatively affects people's health. Bakery products traditionally occupy a significant part in the diet. Sweet potato is a promising ingredient in the enrichment of bakery products.

2. An analysis of the data of finished products obtained by adding sweet potato powder obtained by infrared drying sweet potato powder (PBIF1) in the dough in an amount of $5 \%$ and $10 \%$ by weight of flour showed that the form stability of the samples increased by $4 \%$ and $2 \%$ compared to with control. When adding sweet potato powder in an amount of $10 \%$, the specific volume increased by $6 \%$, porosity - by $3 \%$, acidity - by $25-37 \%$ compared with the control.

3. It was found that when making juice from sweet potato in an amount of $50-70 \%$, the specific volume of products increased by $9-21 \%$ compared with the control sample.

The largest specific volume was possessed by products with the addition of sweet potato juice in an amount of $70 \%$ instead of the mass of water according to the product recipe. The acidity of bread increased by $6 \%$ in samples with the introduction of juice for 50 and $60 \%$, and by $12 \%$ in the bread sample with the introduction of juice for $70 \%$. The porosity of the crumb of bread increased slightly.

4. An analysis of the studies of the physicochemical parameters of bread with the addition of juice from sweet potato showed that the products with the addition of $70 \%$ (SB) by weight had the best indicators. Analyzing the organoleptic characteristics presented in table 4 , we can notice a positive effect (SB) on all indicators: the bread had a convex, light yellow crust, elastic, rich yellow crumb with a reddish tinge and characteristic of sweet potato flavor.

5. A new methodology has been developed for determining the rational (weighted average) dose of powder and sweet potato juice in bread.

\section{References}

[1] O.L. Parrado Alvarez, Variability of a number of features in sweet potato Jpomo Ca batatas (L), Lam in connection with selection for resistance to Gylas formia Carius var Elegantulus, Abstract of the dissertation of the candidate of agricultural sciences, TCHA, 16 (1987).

[2] L.P. Pashchenko, New products with the addition of legumes, Bread products, 10, 50-51 (2010).

[3] V.M. Ponomarenko, P.A. Fedorova, The use of functional additives and non-traditional types of raw materials, Scientific journal NRU ITMO, Series Processes and Food Production Equipment, SPb.: NRU ITMO, 1, 329-333 (2011).

[4] V.M. Ponomarenko, P.A. Fedorova, Studying the effect of protein-containing additives on the quality of wheat bread prepared from flour with reduced baking properties, Izvestiya SPBGAU, 37, 231-238 (2014).

[5] A.F. Fedorov, Biological features of development and yield of sweet potato, Jpomola batatas L, in the conditions of the Western Urals, New and unconventional plants and prospects for their use, Mater. International Symposium, 2, 155-157 (2003).

[6] N.I. Chanukah, Biochemical characteristics of sweet potatoes depending on the cultivation areas, Actual problems of science in agricultural production, 40-41 (1997).

[7] N. Churilin, I. Matveeva, Z. Popova, Unconventional raw materials in the baking industry, Bread products, 9, 26-28 (2004).

[8] G.G. Yusupova, O.N. Berdyshnikova, Methods of flour quality control by rheological properties, Bakery in Russia, 1, 17-18 (2010). 
[9] G.G. Yusupova, O.V. Sinelnikova, Ensuring microbiological safety of grain bread, Bakery of Russia, 1, 22-23 (2011).

[10] G.G. Yusupova, R.Kh. Yusupov, Experiment planning Analysis and Processing: Textbook, St. Petersburg: Mediapapir, 108 (2019).

[11] A.G. Bovel-Benjamin, Ma Cros Copi C and sensory evalua-tion of bread supplemented with sweet potato fl our, J. Food S Si., 69, 167-173 (2004).

[12] M.P. Cereda, F.A.D. Son Cei Cao, A.M. Cagliari, A.M. Huzen, R. Fioretto, Comparative study of sweet potato, Ipomo $\mathrm{Ca}$ batatas, varieties to estimate their utilization in the food industry, Portuguese Furrialba, 32, 4, 365-370 (1982).

[13] C.B. Ndangui, Production et caracterisation de farme de patate douce, Ipomoeabatatas.Lam, optimization of the technologie of panification, 134 (2015).

[14] H-H. Cheng, Protein Content and amino a Cid Composition in tubes and stems and leaves of sweet potato Cultivars, Chinese. J. Agri C. Re. China, 27, 4, 291-295 (1978).

[15] R.L. Villareal, S.C.S. Tsou, S.K. Lin, S.C. Chin, Use of sweet potato, Ipomo Ca batatas, leaf tips as vegetables, II Evaluation of yield and nutritional quantity, Expte. Agri C., 15, 2, 117-122 (1979b). 